International Journal of Accounting and Financial

Management Research (IJAFMR)

ISSN (P): 2249-6882; ISSN (E): 2249-7994

Vol. 10, Issue 1, Jun 2020, 37-44

(C) TJPRC Pvt. Ltd

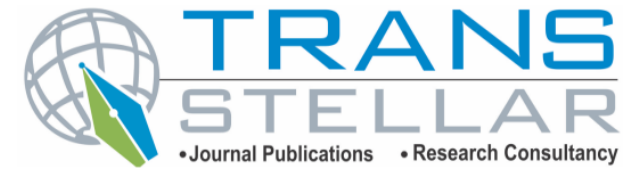

\title{
CONCEPT OF GREEN ACCOUNTING AND ITS PRACTICES IN INDIA
}

\section{MARIA MONICA. M}

Professor, Head of the Department (HOD), Commerce \& Management, St. Vincent Pallotti College, Bengaluru, India

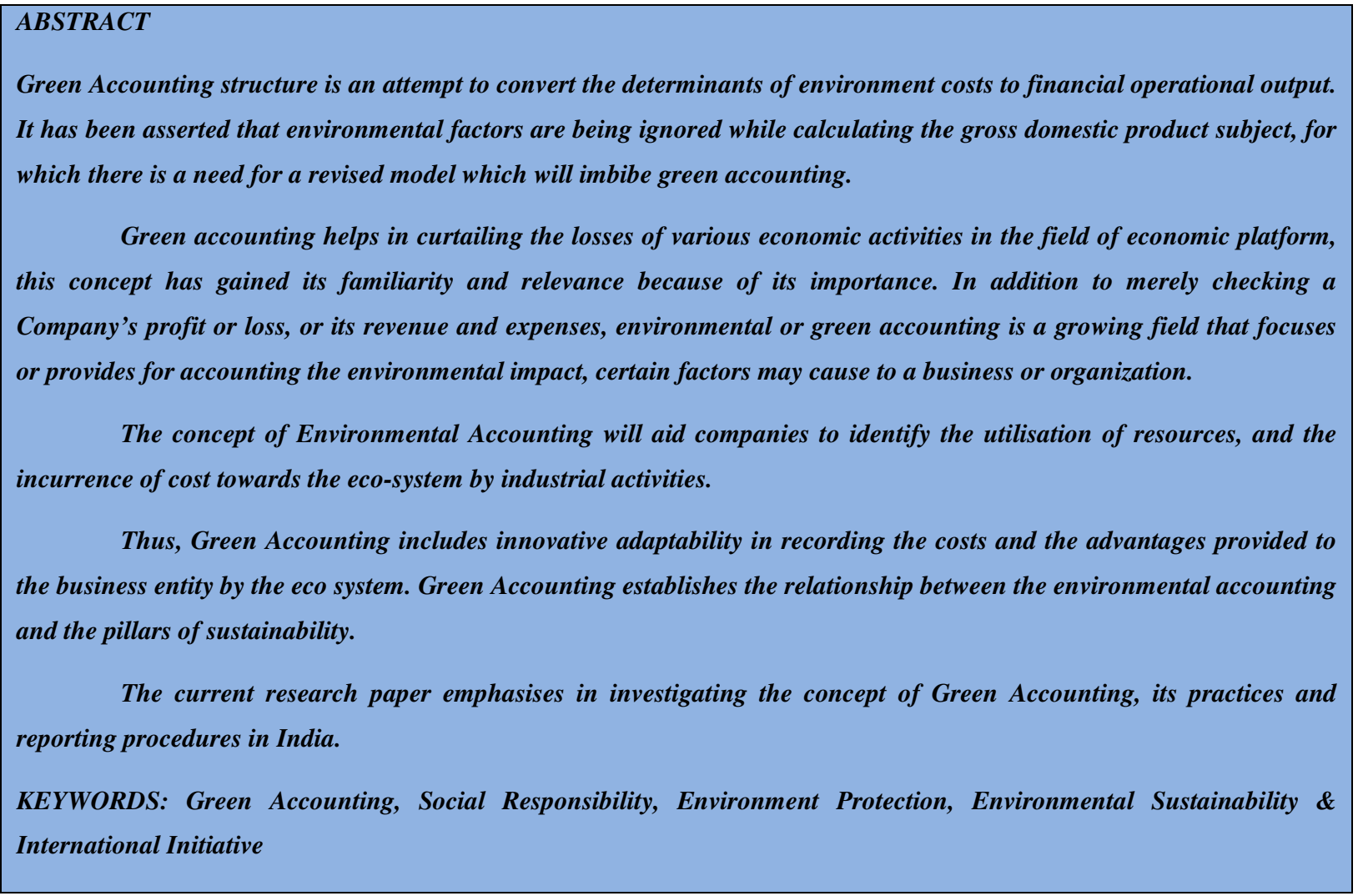

Received: Apr 24 2020; Accepted: May 15, 2020; Published: Jun 12, 2020; Paper Id.: IJAFMRJUN20205

\section{INTRODUCTION}

The term Environmental Accounting was used first time in the year 1980's by Prof. Peter Wood. Green Accounting or Environmental Accounting is an innovative stream of accounting that has an objective of accounting for the environment and its developmental well-being.Although this is a new stream of study and practice, it is gaining quick visibility due to its significance. Accounting, generally establishes itself in recording and verifying a company's income statement or its revenues and expenditures, green accounting is a booming technique in the field of accounting, that mainly focuses on prioritising or providing the accounting information,the impact of environment and the factors which may cause to business organisations.

The nomination of green accounting projects the adherence, an enterprise has towards the environment, and it deals with three vital factors namely people, profit and planet.

\section{OBJECTIVES}

- To explain the concept of green accounting. 
- $\quad$ To know various forms of environmental accounting.

- To explain the various applications terms and process of environmental accounting.

- To know international initiative in environmental accounting.

\section{REVIEW OF LITERATURE}

Over the period of time, the entities started realising the advantages of green reporting. As an impact, there has been a gradual increase in the reporting methodologies by different entities. Early correspondents are shifting to discern that environmental revelation is more of a strategic problem and governance than a subtle tool for reporting (Roome \& Parker, 1992,1997).

In any case of the reporting tool, entity is bound to fulfil the reporting standard requirements of national specification and international standards. It is vital to understand as to how long the benchmark of standards improve the credibility in reporting norms through major research. Nevertheless, most of the researches are based on the analysis of the contents present in the annual reports of the entities.

P, M. (2008). Corporate Environmental Reporting on the Internet.Reflects upon establishing the scope of reporting of green accounting as it prevails. This study was structured on the sample of 24 documents inclusive of entities, annual reports covering the sustainability of relevant reports of past years. At the start of the study, the entities were bifurcated as non-manufacturing and manufacturing sectorial units, there were few entities operational in both the sectoral units and the categorization was done depending upon the basis of central operation carried out by the entities.

Another study undertaken by HariPriya (2005) in her article titles "The Methodology of Green Accounting for India and its States" throws light about the structure and governance of accounting across the nation emphasising on the net increase in the wealth of state and projecting an appropriate method of reduction of natural capital expenditure factors in national accounts by measuring the depreciation and reduction in the usage of natural resources, projected pollution costs, educational rewards additional to capital human stock.

\section{RESEARCH METHODOLOGY}

Type of Research: Descriptive

Data Base: The current analysis is based on secondary sources data and information has been extracted from various websites and research articles.

\section{Scope of Green Accounting}

Green accounting involves estimation and capitalisation of environmental cost/expenditures, identification and measurement of environmental liabilities.

\section{Environmental costs / Expenditures}

These are costs/ expenditures inline to the measures of the environment that includes costs relate to production, research of a product and developmental expenditures incurred predominantly for ensuring the protection of the environment.The overall expenditure confined to environment can be categorised into six types such as the capital investment, operating costs, research and developmental costs, planning, environmental administrations and expenditures relating to the recovery and remedial measures. 


\section{Capitalization of Environmental Expenditures}

Following are the examples for environmental expenditures - extension of cost over the life of an asset, expenses incurred on quality assurance, safety of property governed and owned by the company, mitigation of costs, prevention of environmental contamination, costs leading to the improvement of the resources or property in comparison to its original condition at the time of acquisition, costs incurred while preparing the property for sale.

\section{Environmental Liabilities}

Environmental liability is the amount set aside to pay future expenses that occur due to the past activities, events or transactions through environmental damages, to compensate the damage suffered by a third party. It may also include an environmental contingent liability that purely depends on the non-occurrence and occurrence of one or multiple futuristic uncertain events or to compensate such losses suffered by third party.

\section{Measurement of Environment Liabilities}

Environmental liabilities are subject to quantify or non- quantifiable categories. Generally, in accounting the quantifiable figures are projected in the balance sheet provided accurate value is available if not the same is projected in the footnote elaborating the characteristic of such liability is necessary.

\section{Forms of green / Environmental Accounting}

\section{(1) Environmental Management Accounting (EMA):}

This type of accounting involves a particular attention on the flow of information towards energy, material and cost of environmental information. Environmental Management Accounting further can be classified into following sub categories:

- Environmental Segment Accounting: This is an intense form of environmental accounting mechanism used in order to select a project, activity confined to investment regarding the conservation of environment from all the operational process and evaluation of environmental effects for a certain duration of time period.

- Eco Balance Environmental Accounting: This is an internal form of green accounting tool that supports Plan Do Check Act (PDCA) for management of sustainable environmental activities.

- Corporate Environmental Accounting: This is a tool to inform public regarding the compilation of relevant information in accordance to the Environmental Accounting. This is called as Corporate Environmental Reporting. For reporting purpose, the cost and effect (in terms of monetary value or quantity) of conservation of environmental activities are used.

\section{(2) Environmental Financial Accounting (EFA)}

It is in line with Financial Accounting that particularly focuses on reporting significant environmental costs and environmental liabilities.

\section{(3) Environmental National Accounting (ENA)}

It focuses particularly on stocks confined to natural resources and flaws involved in it alongside the externality and environmental costs. 


\section{The Objective of Imbibing Green Accounting at Industrial Level}

Is to identify if corporation has been in a position to discharge the duties and responsibilities towards environment.

\section{Company has to Fulfil the Following Responsibilities Confined to Environment:}

- $\quad$ Meeting or exceeding the expectation of regulatory requisites.

- Disposal of hazardous material and reduction of increasing pollution.

- Disclosure of current and potential amount of preventive measures taken by the entity to protect the environment. Mandatory disclosure, if the estimated liability is greater than $10 \%$ of the entity's net worth.

- The entities must be managed effectively and due consideration must be taken in managing operational activities so that environmental damages can be avoided.

- $\quad$ Promotion of entity's holding wide range of environmental awareness programmes/ campaign.

- $\quad$ Effective control on material and operational gain in efficiency driven by the competitive global market.

- Cost control over increasing raw materials, management of waste and potential liability.

\section{Terms, Process and Application of Environmental Accounting}

One of the general conditions for application of environmental accounting into an entity is to harmonize its environment. The minimum prerequisites that an entity must hold are mentioned below:

- $\quad$ Ensuring to support top level management

- $\quad$ Setting environmental culture

- Acknowledging the fact that entity-based activities damage the environment

- $\quad$ Evaluating the impact of environment on projects.

- Offering training confined to environmental protection. training all its employees.

- Integration of quantifying environmental accounting and a briefingabout what is quantified and why it is required to quantify.

- Technological training for such quantification and documentation of the same.

- Establishing a structural reporting system to describe the performance measurement data required to interested groups

- Constant check on reporting system to ensure reliability confined to the reported data

After the fulfilment of applying the conditions of the environmental, accounting and application procedure is then realized. The process of procedure includes nine stages. These are as follows:

- Development of input and output modelling analysis for the utilisation of raw materials and energy sources.

- $\quad$ Brief description and understanding of the environmental costs 
- Constant monitoring, recording and reporting of non-financial data confined to primary raw materials and flow of energy at the entities.

- Adopting models of decision making and predicting the cost of environment and sensitivity.

- Utilisation of advanced innovative technology for the allocation of environmental costs to its organizational units' processes and its product costs.

- Extension of wide scope of environmental accounting and value chain analysis over a long period.

- Reaching environmental perfection through external report and evaluation of the same utilising the interested group of employees.

- Efforts taken to reach the threshold of sustainable development.

- The concept of "sustainability" should speak the same language as "environmental perfection" this is because the environmental protection focuses on reducing wastes and pollution, while sustainable development predicts on the fair distribution of environmental costs and adds as an advantage among people especially with reference to future generations.

\section{LEGAL FRAMEWORK FOR ENVIRONMENTAL ACCOUNTING IN INDIA}

Concerns are increasing all over the globe in the past two decades, regarding environmental protection and upholding antipollution.

\section{Accounting Requirement}

Gazette Notification on Environmental Auditing is issued by the Ministry of Environment and Forests in the year 1992 (which is amended vide notification GSR386 (E) dated 22/04/1993), under the Environmental Act, 1986 which mandated all the units of industries to submit its environmental status concerning the State Pollution Control Board, while requesting the consent to function according to the similar environment rule. Statement confinedto eco-system has to framed in order to undertake deep action as this will help in the structural flow of business cycle starting from procurement of material, to reducing and recycling industrial waste as it necessarily saves cost of material.

The Companies Act, 1956 of India insists to include environmental related concerns or policies in the Director's report

Central Government mandates to maintain Cost Accounting by recording and disclosing various quantitative values maintained across industries. The State and Central government has passed statutes to abide and keep track of environmental hazards and ecological disruptions.

\section{Global Stand in Environmental Platform}

Analysing the global platform, the progression on designing environmental accounts had been underway since the 1970's. In 1980's, United Nations Environmental Program (UNEP), United Nations Statistical Division (UNSTAT) and World Bank staged global effort to harmonise on how SNA (System of National Accounts) could be transformed to include issues prevalent in environment. As an output, in the year 1993, a draft titled Handbook for integrated Economic and Environmental Accounting was published, revolved the preliminary methodology to be tested and tuned. The approach in 
this documentation is referred as a System of Integrated Economic and Environment Accounting (SEEA). SEEA tries to blend various categories available for environmental accounting into a single frame. This document offers a series of versions for the establishment of accounts beginning with physical accounts and disaggregation of data included in System of National Accounts. It also works towards more composite data such as calculation of depletion costs and estimation of maintenance costs required for sustainable utilisation of resources.None of the categories mentioned in SEEA enclose the evaluation of environmental act of assistance that are phenomenally non-marketed. United Nations Statistical Division along with United Nations Environmental Program and other authorities are putting their attempts in developing practical hand book or work book for implementation of System of Integrated Economic and Environment Accounting - it engulfs as inappropriate methodology and does not have an official approval from the UN. This is to be studiedover the periodfor establishing a clarity in the structural systemthrough intense research.

\section{CONCLUSIONS}

Although Green Accounting is gaining its stardom in terms of natural resources and environmental accounting by incorporating the environmental assets and sources of the same alongside its sunk functions into corporate accounting, the pathway to environmental protection and redemption of human rights violation has a wide tread towards its legacy that takes on many diversions such as concepts, conventions, entities, institutions, legal framework and defence based military actions. For all the mentioned concepts, the international community still battles with the expertise of creating harmony as well as safeguarding human self-esteem.

If Green Accounting is sternly instrumentalised in all the categorical levels of the management organisations, there can be drastic changes towards the progression of the environment. Due to exhaustion of the natural resources, the system of green or environmental accounting facilitates in tracking such usage and keeps accountability on ample utilisation of the same with minimal costs.

\section{REFERENCES}

1. http://www.techjini.com/blog/green-accounting/

2. http://www.yourarticlelibrary.com/economics/ environmental -economics/ green- accounting need-objectives-problems-andother - details/39675/

3. Mehta, P. A. L. L. A. V. I., and K. H. U. S. H. B. U. Mehta."Green HRM practices and organizational culture." International Journal of Human Resources Management 6.1 (2017): 1-6.

4. https://www.fujifilmholding s.com/en/sustain ability/ steps/ sustainability /accounting.html

5. Pallavi, Evpas, and MVV Bhanu. "Green HRM: A Way for Corporate Sustainability." (2016).International Journal of Human Resource Management and Research (IJHRMR) 6.2, Apr 2016, 13-20

6. http://smallbusiness.chron.com/advantages-disadvantages-green-manufacturing-businesses 22312.html

7. https://www.uniassignment.com/essay-samples/accounting/what-is-environmental-accounting-accounting-essay.php

8. Asaduzzaman, M., M. K. Hamid, and S. A. M. I. N. A. Afrin. "Corporate Environmental Reporting (CER) practices: empirical evidence from selected non-financial companies in Bangladesh." International Journal of Business and general Management 3.1 (2014): 1-8.

9. Haripriya Gundimeda (2005). TERI Press, December 
10. Malarvizhi P, (2008), CorporateEnvironmentalReporting on the Internet: An Insight into Indian Practices, Indian Institute of Technology, Kanpur, India.

11. Hosain, M. D. "The impact of E-HRM on organizational performance: Evidence from selective service sectors of Bangladesh." International Journal of Human Resources Management (IJHRM) ISSN (P) (2017): 2319-4936.

12. The European Commission (2011). Green Accounting as a path to a sustainable future.

13. Lehman, Glen. (2011). The Management of Sustainability: The Art of Interpretation. JAMA, 9(1), 23-37 
